\title{
The Role of Nitric Oxide in Immune Response Against Trypanosoma Cruzi Infection
}

\author{
Wander Rogério Pavanelli ${ }^{*}$, and Jean Jerley Nogueira Silva*,2 \\ ${ }^{I}$ Department of Pathology Science, CCB, State University of Londrina-UEL, Londrina, PR, Brazil; ${ }^{2}$ Department of \\ Physic and Informatics, Institute of Physic of São Carlos, University of São Paulo, Brazil
}

\begin{abstract}
Nitric oxide (NO) is a free radical synthesized from L-arginine by three different NO-synthases (NOS). NO exhibits multiple and complex biological functions and many of its effects can be mostly attributed to its strong oxidant capacity, which provides it a high affinity to metals, mainly metal with low spin configuration. Molecular targets of NO are diverse and include both low molecular weight species (e.g. thiols) and macromolecules that can be either activated or inhibited as a consequence of reacting with NO. Thus, NO is an important mediator of immune homeostasis and host defence, and changes in its generation or actions can contribute to pathologic states. The knowledge of novel effects of NO has been not only an important addition to our understanding of immunology but also a foundation for the development of new approaches for the management and treatment of various diseases, including Chagas' disease. Herein, the multiple mechanisms by which NO can directly or indirectly affect the generation of an immune response against $T$. cruzi infection are discussed.
\end{abstract}

Keywords: Nitric oxide, immune response, T. cruzi.

\section{INTRODUCTION}

Nitrogen monoxide, also called nitric oxide (NO) is a radical with a small molecular weight $(30 \mathrm{kDa})$ that performs multiple biologic activities. The biological importance of this ubiquitous intra and intercellular signalling molecule was first described in the early 1980s, as being part of the "endothelial derived relaxing factors" (EDRF) [1, 2]. It was named 'Molecule of the Year' in 1992 by the journal Science, and later in that decade, studies were conducted to demonstrate the cardinal mechanism of action of NO on vascular smooth muscle, which made clear that NO generated by endothelial cells causes relaxation of smooth muscle through activation of granulate cyclase by nitrosation of its heme [3, 4], and conferred the Physiology and Medicine Nobel Prize to Murad, Furchgott, and Ignarro in 1998 [5]. Since its discovery, an increasing number of studies have attempted to address the biochemistry of this freely diffusible second messenger and the connections with its biological properties. As a consequence, it became the focus of intense biological and clinical research [6, 7]. Beforehand, it was believed that NO would predominantly regulate guanylate cyclase activity. However, this view has been altered fundamentally by a spate of recent findings indicating that NO may target cysteine thiols and transition-

"Address correspondence to these authors at the Universidade Estadual de Londrina, Rodovia Celso Garcia Cid, Campus Universitário, CP 6001, Londrina, PR, CEP 86051-990, Brazil; Tel: +55 433371 4000;

Fax: +55 433328 4440; E-mail: wanderpavanelli@usp.br

Universidade de São Paulo, Av. Trabalhador São-carlense 400, CP 780, São Carlos, SP; CEP 13566-970, Brazil; Tel: +55 163373 9868; Fax: +55 16 3373 9881; E-mail: jjerley@yahoo.com.br

This paper is based on a part of the postdoctorate-visiting research of Pavanelli, WR. metal centres of proteins with exquisite spatial and temporal resolution. Such structural modifications may modulate protein function as cGMP-independent cellular-control signal transducer. The discovery of these guanylate cyclaseindependent effects renewed the paradigmatic enthusiasm around NO. Among these novel effects, it has been demonstrated that $\mathrm{NO}$ is also able to induce dynamic posttranslational regulation of almost all major classes of micro and macromolecules, acting as a master chemical regulator of several biological functions [8], in a process that could be compared to protein phosphorylation. This re-emergence of scientific interests on NO has provided new insights on the molecular mechanisms such as, cellular and humoral immune responses [6]. As a consequence, pharmaceutical industries have shown increased interest in NO manipulation in the last years and in the future, this free radical could be used as a potential therapeutic target in a vast variety of conditions, ranging from inflammation to degenerative diseases.

It is known that $\mathrm{NO}$ can directly and indirectly modulate the immune response through diverse mechanisms as mediating microbicidal effects of NO-derived free radicals, mostly within macrophages and other phagocytes. Modulation of effector mechanisms of leukocytes during the infection has been also observed. However, due to its regulatory effects, $\mathrm{NO}$ exhibits a dual role in the elicited response, dictated by the concentration in the inflammatory microenvironment. Of note, a deregulated NO production is observed in infected individuals, which is associated with collateral toxicity for host cells, leading to immunopathology, autoimmune responses or persistence of parasite due to immune evasion. 


\section{EFFECTS OF NITRIC OXIDE IN THE IMMUNE SYSTEM}

The versatility of the effects of NO on cell biology have started to become clearer as recent insights on the chemistry of the complex interactions between NO (and its mediators) and biomolecules have been revealed. Three types of global NO-mediated functions have been classically recognized: (i) endothelium dependent relaxation [1] (ii) neurotransmission $[9,10]$ and (iii) cell-mediated immune response [11]. Initially, it was thought that these mechanisms involved the direct activation of guanylate cyclase, leading to generation of cGMP, followed by the kinase-mediated signal transduction [12]. While most of the messenger functions of NO are based on cell-specific expression and stringent regulation of calcium-dependent NO-synthases (cNOSs) (type 1 and 3), enhanced expression of calcium independent iNOS activity have been observed in response to infectious agents in a wide variety of cells from mice and humans. In the immune system, NO mediates host protection through either directly, as a microbiostatic or microbicidal agent, or indirectly, modulating chemical modifications of crucial for the biological activity of innate and acquired immunity cell lines [13]. NO also participates in the maintenance of inflammatory diseases (i.e. arthritis, ulcerative colitis, Crohn's disease). The intensity of inflammatory symptoms (erythema, vascular leakiness) is related to the production of NO, and can be reverted by NOS inhibitors [14, 15]. Nonetheless, in chronic immune responses the immune regulatory role of NO appears to correlate with pathogen persistence $[16,17]$.

Under homeostatic conditions, NO is produced in low concentrations from constitutive NO synthases and acts as an intracellular messenger and cytoprotective (antioxidant) factor. In fact, hyper-expression of endothelial NOS (eNOS) blocks the exocytosis of mediators of inflammation from the endothelial cell, thus blocking inflammation in blood vessels. Conversely, under circumstances of inflammatory stimuli, the formation of substantial amounts of NO (for example, in response to a intracellular infection), along with modification of the cellular microenvironment (i.e. formation of the superoxide radical) facilitate both direct and indirect effects of NO, as a consequence of the formation of dinitrogen trioxide and peroxynitrite, which only occurs at the sites of simultaneous superoxide formation, such as in phagocytes [18-20].

\section{Microbial Toxicity of Nitric Oxide}

One of the most prominent functions of NO in immune system is its participation in protective immunity against various intracellular pathogens including viruses, bacteria and protozoa [11, 21-34]. Furthermore, the killing activity of NO has also been showed effective in host defence against tumour cells [35] and alloantigens [36]. Considering its direct microbial toxicity, $\mathrm{NO}$ can exert a microbiostatic or microbicidal effect, or even act as a microbial metabolic products [13]. In spite that these direct cellular effects of NO over pathogen biology are not yet fully understood, the strong oxidative capacity of $\mathrm{NO}$ and its sub-products appears to act in synergism with other lethal reactive oxidant species $\left(\mathrm{H}_{2} \mathrm{O}_{2}\right.$, etc), accounting for most of the host's microbial toxicity. Indeed, the simultaneous production of $\mathrm{NO}$ and superoxide $\left(\mathrm{O}_{2}\right)$ by activated macrophages leads to formation of peroxynitrite anion $\left(\mathrm{ONOO}^{-}\right)$, which constitutes a harmful agent against a diverse variety of pathogens. $\mathrm{ONOO}^{-}$induces modifications of selected molecular targets on parasite, being a major mechanism for direct effects of NO, and such targets are starting to be revealed [8, 37-39]. Peroxynitrite can induce nitration of residues of tyrosine as well as the reversible binding of NO to metal centres in microbial targets that are involved in vital processes, such as nutrition and respiration among others. In infection diverses, cysteinecontaining proteins, metalloproteins, calcium transport systems [40], as well as essential enzymes of energy metabolism [41] have been identified as important intracellular targets for the toxic actions of peroxynitrite. Among them, cysteine proteinases are critical factor for virulence or replication of many pathogens (including viruses, bacteria, fungi, and parasites) [42-44].

Depending on the individual characteristics of molecules, it can lead to either the activation or inactivation of the respective protein function. Exacerbated production of NO and the consequent exaggerated levels of "reactive nitrogen species" (RNS) can unbalance the homeostatic mechanisms of the host, mediating collateral host toxicity and this could be the fundament for certain pathologies related to nitrosative and oxidative stress [45-47]. Indeed, the presence of nitrosylated tyrosine residues (Nitro tyrosine) has been recognized as an indicator of cell damage and inflammation, as well as of the production of $\mathrm{ONOO}^{-}$. In addition to the direct toxicity, novel effects of NO over leukocyte biology have been recently described, which can influence several physiologic processes ranging from DNA transcription [48] and replication [49] to protein synthesis [50] and secretion. The signalling processes through which NO acts to regulate immune cells are extremely complex and are only just beginning to be revealed, but are largely indirect through generation of reactive nitrogen oxide species that chemically modify enzymes, signalling proteins and transcription factors. The role of NO might depend on the stage of a disease (i.e., early or late disease stages). And for a given cell, the response to $\mathrm{NO}$ will depend on its reactivity state and on the microenvironment as well.

\section{IMPLICATIONS ON THERAPEUTICS}

Pharmacological manipulations of NO production have greatly contributed to the understanding of the physiological effects of this mediator [51]. Some of these compounds have promising properties and may enter in the clinical field, providing important therapeutic benefits in inflammatory or infectious diseases. For example, classical NO donors such as SNAP (S-nitroso-acetyl-penicillamine) and SNP (sodium nitroprusside) cause pathogen killing in models of parasite diseases, probably by inactivating vital molecules in the microorganism, as a consequence of the NO generated [52]. In fact, SNAP and SNP were able to inactive essential cysteine parasite enzyme from several pathogens such as Trypanosoma, Leishmania, and Plasmodium. The duality of NO in induce or regulate apoptosis of immune cells can be of therapeutic interest. Indeed, depending on concentrations, the NO donor SNAP can switch from blocker of apoptosis to an inducer of necrosis in Jurkat $\mathrm{T}$ cells exposed to antiCD95. Consequently, the final outcome (whether a cell will undergo apoptosis or necrosis) is closely regulated by the 
intensity of the stimulus and the amount of induced NO production. This is in part due to the fact that the impact of NO on cell homeostasis and death are complex and often even appear to be contradictory. NO may be cytotoxic but may also protect cells from a toxic insult; it is apoptosisinducing but also exhibits prominent anti-apoptotic activity. NO is an antioxidant but may also compromise the cellular redox state via oxidation of thiols such as glutathione. NO may activate specific signal transduction pathways but is also reported to inhibit exactly these, and NO may activate or inhibit gene transcription. The situation may even be more complex, once NO, depending on its concentration, may react with oxygen or the superoxide anion radical to yield reactive species with a much broader chemical reaction spectrum than NO itself. Thus, the action of NO during inflammatory reactions has to be considered in the context of timing and duration of its synthesis as well as stages and specific events in inflammation [53].

NO can also protect the host from wasting and maintain the homeostasis in the host immune system, through its micro vascular, cytoprotective, immunoregulatory, and antimicrobial properties, mostly because the redox versatility of $\mathrm{NO}$ allows for its inter-conversion from protective to toxic species by a change in the ambient redox milieu. So the raising question is about how to modulate the activation of NO synthesis until a point that is sure enough to avoid tissue destruction. Removal of apoptotic cells (AC) by professional phagocytes is an important mechanism by which some pathogen-induced cell alterations are ultimately detected and also is one of the factors involved in recycling some cell constituents. This uptake of apoptotic cells is not expected to rice an inflammatory response. In accordance, macrophages up regulate the arginase II enzyme after phagocytosis of apoptotic cells, which regulates NO production from iNOS [54]. However, this process can also be exploited by T. cruzi [55], favouring the invasion of uninfected cells by the parasite.

Sometimes, immune intervention strategies target iNOS as a key mediator for tissue damage in inflammatory diseases. Approaches of this type needs to consider that NO also acts to limit destructive Th1 responses. In those cases where the regulatory role of iNOS exceeds its cytotoxic function, inhibition of iNOS will exacerbate rather than suppress the disease. Recently, several xenobiotic chemicals have been found to modulate iNOS expression [56]. Important future directions will focus on molecular mechanisms of action of NO, its target molecules and cells and its role in infection and immunological mediated diseases.

\section{NITRIC OXIDE AS MODULATOR OF IMMUNE RE- SPONSE AGAINST T. CRUZI}

During T. cruzi infection, NO can directly or indirectly modulate the effector leukocyte machinery through diverse mechanisms. This process involves microbicidal effects derived from toxic-free radicals (peroxinitrite and superoxide) generated after NO production, as well as regulation/enhancement of the inflammatory response induced during this type of infection, a dual role in the immunity that is usually observed for NO.
NO production is perhaps the most important among these early produced mediators and has been reported to display anti-parasitic activity. In fact, in T. cruzi infection, NO is involved in the control of T. cruzi-induced parasitemia and directly kills the parasite in vitro [57]. NO modulates the $T$. cruzi-induced myocardial inflammatory reaction, mechanism dependent of NOS isoforms [58], and potentially reducing cardiac lesions during the acute phase of Chagas disease [59].

Some studies, have reported that NO affects $T$. cruzi by chemically modifying cysteine-containing proteins and/or by binding to metalloproteins that mediate crucial metabolic processes. It was reported that $\mathrm{NO}$ or NO donors can inhibit the catalytic activity of cruzipain, the major papain-like cysteine proteinase in $T$. cruzi $[60,61]$.

NO has been demonstrated to be the principal effector molecule involved in macrophage-mediated killing of $T$. cruzi amastigotes [62-64]. In accordance, macrophages up regulate the arginase II enzyme after phagocytosis of apoptotic cells, which regulates NO production from iNOS [65]. In addition, $T$. cruzi has an extremely complex surface antigenicity conferred by Glycophosphatidylinositol-anchored mucin-like glycoproteins (GPI) [66], that are potent inducers of NO by IFN- $\gamma$ primed macrophages [67]

An additional mechanism by which NO can affect the metabolism of $T$. cruzi is through the reduction of available growth factors. For example, iron is an important growth factor for $T$. cruzi [68].

Recently we have shown that ruthenium complexes of the type trans-[Ru(NO)(NH$\left.)_{4} \mathrm{~L}\right]^{\mathrm{n}+}$ which act as releasers of NO are able to lyse T. cruzi in a manner dose-time dependent [69]. On further investigation, it was possible to observe that when the doses of $10,50,100,400 \mathrm{nmol} \mathrm{kg}^{-1}$ of each compound were administered by intraperitoneal route for 15 consecutive days, these compounds were able to reduce the parasitemia, cardiac inflammation and also allowed increased survival of infected mice. According to these data [70], the parasitemia was reduced when the complexes were administered in concentrations of the order of nanomolar concentrations, with near ideal dose of $400 \mathrm{nmol} \mathrm{kg}{ }^{-1}$. Furthermore, when doses above of $1 \mu \mathrm{mol} \mathrm{kg}{ }^{-1}$ were administered, the complex in question showed the opposite effect increasing in some doses (e.g.: $3 \mu \mathrm{mol} \mathrm{kg}{ }^{-1}$ ) the number of parasites per milliliter of blood with respect to those treated only with PBS. As a result, the final percentage of survival after 60 days ranged between 20 and $100 \%$ for doses in nanomolar concentrations whereas $0 \%$ of survival was observed for concentrations of the order of micromolar.

This antagonistic effect of NO, sometimes controlling the infection by T. cruzi in vivo now helping the parasite to replicate, it may at first sound contradictory. However, as mentioned above, the physicochemical properties of NO confer unique skills at the same time may be beneficial or deleterious. It has been reported that the endogenous production of NO exerts cytostatic and cytotoxic effects for the T. cruzi [71]. However, such production requires a strict control of its concentration in vivo in order to limit the damage caused to the cytotoxic cells of the host, since the free NO has multiple functions, and is very specific [72]. Often, the effects of protection and the toxic effects of $\mathrm{NO}$ are observed during the 
infections caused by parasites such as $T$. brucei and $T$. cruzi [72]. When the trypomastigote forms invade the cytosol of macrophages where they transform into amastigotes and the infection of these circumstances triggers a moderate production of interleukin-12 (IL-12) and of tumor necrosis factoralpha (TNF- $\alpha)[73,74]$. These cytokines lead to the synthesis of interferon gamma (INF- $\gamma$ ) and consequently the activation of iNOS [75]. Thus, NO is synthesized and its production has been attributed as responsible for tripanocida activity of activated macrophages. However, at this stage of the parasite infection also triggers the production of transforming growth factor beta (TGF- $\beta$ ) and interleukin-10 (IL-10) which are negative regulators of the production of NO [76], and thereby inhibiting the activation of macrophages once activated by INF- $\gamma$. Moreover, the production of TGF- $\beta$, which has been described as an important inflammatory response, often exacerbates the infection promoted by $T$. cruzi [75]. Additionally, it has been reported that the unregulated production of NO during the acute phase of chagasic infection also plays an important role facilitating the parasite's evasion of host immune system [77]. Finally the NO can also suppress the host immune response through induction of apoptosis of $\mathrm{T}$ cells [78].

Therefore, NO is essential for host survival during acute experimental $T$. cruzi infection. Its production is rapidly triggered in cells of the innate immune system, after the parasite is detected and later by adaptive immune cells. A delicate, yet not completely understood, interplay exists between the components of the immune response and the concentration of NO.

\section{ACKNOWLEDGMENTS}

The authors would like to acknowledge the financial support from Fundação Araucária, Coordenação de Aperfeiçoamento de Pessoal de Nível Superior (CAPES) and Special Programme for Research and Training in Tropical Diseases (TDR/WHO).

\section{REFERENCES}

[1] Furchgott, R.F.; Zawadzki, J.V. The obligatory role of endothelial cells in the relaxation of arterial smooth muscle by acetylcholine. Nature, 1980, 288, 373-376.

[2] Moncada, S.; Radomski, M. W.; Palmer, R.M. Endotheliumderived relaxing factor. Identification as nitric oxide and role in the control of vascular tone and platelet function. Biochem. Pharmacol., 1988, 37, 2495-01.

[3] Ignarro, L.J. Biosynthesis and metabolism of endothelium-derived nitric oxide. Annu. Rev. Pharmacol. Toxicol., 1990, 30, 535-560.

[4] Ignarro, L.J. Haem-dependent activation of guanylate cyclase and cyclic GMP formation by endogenous nitric oxide: a unique transduction mechanism for transcellular signaling. Pharmacol. Toxicol., 1990, 67, 1-7.

[5] Murad, F. Cyclic guanosine monophosphate as a mediator of vasodilation. J. Clin. Invest., 1986, 78, 1-5.

[6] Moncada, S.; Palmer, R.M.; Higgs, E.A. Nitric oxide: physiology, pathophysiology, and pharmacology. Pharmacol. Rev., 1991, 43, 109-142.

[7] Lancaster JR, Jr. Simulation of the diffusion and reaction of endogenously produced nitric oxide. Proc. Natl. Acad. Sci. U. S. A., 1994, 91, 8137-8141.

[8] Hess, D.T.; Matsumoto, A.; Kim, S.O.; Marshall, H.E.; Stamler, J.S.; Protein S-nitrosylation: purview and parameters. Nat. Rev. Mol. Cell Biol., 2005, 6, 150-166.

[9] Garthwaite, J.; Charles, S.L.; Chess-Williams, R. Endotheliumderived relaxing factor release on activation of NMDA receptors suggests role as intercellular messenger in the brain. Nature, 1988, $336,385-388$.
[10] Gillespie, J.S.; Liu, X.R.; Martin, W. The effects of L-arginine and NG-monomethyl L-arginine on the response of the rat anococcygeus muscle to NANC nerve stimulation. $B r . \quad J$. Pharmacol., 1989, 98, 1080-1082.

[11] Nathan, C.F.; Hibbs, J.B.Jr. Role of nitric oxide synthesis in macrophage antimicrobial activity. Curr. Opin. Immunol., 1991, 3, 65-70.

[12] Ignarro, L.J.; Byrns, R.E.; Wood, K.S. Endothelium-dependent modulation of cGMP levels and intrinsic smooth muscle tone in isolated bovine intrapulmonary artery and vein. Circ. Res., 1987, 60, 82-92.

[13] Heck, D.E.; Kagan, V.E.; Shvedova, A.A.; Laskin, J.D.; An epigrammatic (abridged) recounting of the myriad tales of astonishing deeds and dire consequences pertaining to nitric oxide and reactive oxygen species in mitochondria with an ancillary missive concerning the origins of apoptosis. Toxicology, 2005, 208, 259-71.

[14] Cattell, V.; Jansen. A. Inducible nitric oxide synthase in inflammation. Histochem. J., 1995, 27, 777-784.

[15] Bucci, M.; Roviezzo, F.; Posadas, I.; Yu, J.; Parente, L.; Sessa, W.C.; Ignarro, L.J.; Cirino, G. Endothelial nitric oxide synthase activation is critical for vascular leakage during acute inflammation in vivo. Proc. Natl. Acad. Sci., U. S. A., 2005, 102, 904-908.

[16] Roberts, F.; Roberts, C.W.; Ferguson, D.J.; McLeod, R.; Inhibition of nitric oxide production exacerbates chronic ocular toxoplasmosis. Parasite Immunol., 2000, 22, 1-5.

[17] Hayashi, S.; Chan, C.C.; Gazzinelli, R.; Roberge, F.G. Contribution of nitric oxide to the host parasite equilibrium in toxoplasmosis. $J$. Immunol., 1996, 156, 1476-1481.

[18] Crow, J.P. Beckman, J.S. The importance of superoxide in nitric oxide-dependent toxicity: evidence for peroxynitrite-mediated injury. Adv. Exp. Med. Biol., 1996, 387, 147-161.

[19] Beckman, J.S.; Koppenol, W.H.; Nitric oxide, superoxide, and peroxynitrite: the good, the bad, and ugly. Am. J. Physiol., 1996, 271, C1424-1437.

[20] Ischiropoulos, H.; Zhu, L.; Beckman, J.S. Peroxynitrite formation from macrophage-derived nitric oxide. Arch. Biochem. Biophys., 1992, 298, 446-451.

[21] Fang, F.C. Perspectives series: host/pathogen interactions. Mechanisms of nitric oxide-related antimicrobial activity. J. Clin. Invest., 1997, 99, 2818-2825.

[22] Nathan, C.; Shiloh, M.U. Reactive oxygen and nitrogen intermediates in the relationship between mammalian hosts and microbial pathogens. Proc. Natl. Acad. Sci. U. S.A., 2000, 97, 8841-8848.

[23] De Groote, M.A.; Fang, F.C. NO inhibitions: antimicrobial properties of nitric oxide. Clin. Infect. Dis., 1995, 21 (Suppl 2), S162-165.

[24] Murray, H.W.; Nathan, C.F. Macrophage microbicidal mechanisms in vivo: reactive nitrogen versus oxygen intermediates in the killing of intracellular visceral Leishmania donovani. J. Exp. Med., 1999, 189, 741-746.

[25] Stenger, S.; Donhauser, N.; Thuring, H.; Rollinghoff, M.; Bogdan, C. Reactivation of latent leishmaniasis by inhibition of inducible nitric oxide synthase. J. Exp. Med., 1996, 183, 1501-1514.

[26] Adams, L.B.; Hibbs, J.B.Jr.; Taintor, R.R.; Krahenbuhl, J.L. Microbiostatic effect of murine-activated macrophages for Toxoplasma gondii. Role for synthesis of inorganic nitrogen oxides from L-arginine. J. Immunol., 1990, 144, 2725-2729.

[27] Brunet, L.R. Nitric oxide in parasitic infections. Int. Immunopharmacol., 2001, 1, 1457-1467.

[28] James, S.L. Role of nitric oxide in parasitic infections. Microbiol. Rev., 1995, 59, 533-547.

[29] Wynn, T.A.; Oswald, I.P.; Eltoum, I.A.; Caspar, P.; Lowenstein, C.J.; Lewis, F.A.; James, S.L.; Sher, A. Elevated expression of Th1 cytokines and nitric oxide synthase in the lungs of vaccinated mice after challenge infection with Schistosoma mansoni. J. Immunol., 1994, 153, 5200-5209.

[30] Nathan, C.; Xie, Q.W. Nitric oxide synthases: roles, tolls, and controls. Cell, 1994, 78, 915-918.

[31] Vespa, G.N.; Cunha, F.Q.; Silva, J.S. Nitric oxide is involved in control of Trypanosoma cruzi-induced parasitemia and directly kills the parasite in vitro. Infect. Immun., 1994, 62, 5177-5182.

[32] Silva, J.S.; Machado, F.S.; Martins, G.A. The role of nitric oxide in the pathogenesis of Chagas disease. Front. Biosci., 2003, 8, s314325 . 
[33] Chakravortty, D.; Hensel, M. Inducible nitric oxide synthase and control of intracellular bacterial pathogens. Microbes Infect., 2003, 5, 621-627.

[34] Clark, I.A.; Rockett. K.A. Nitric oxide and parasitic disease. $A d v$. Parasitol., 1996, 37, 1-56.

[35] Cifone, M.G.; Cironi, L.; Meccia, M.A.; Roncaioli, P.; Festuccia, C.; De Nuntiis, G.; D'Alo, S.; Santoni, A. Role of nitric oxide in cell-mediated tumor cytotoxicity. Adv. Neuroimmunol., 1995, 5, 443-461.

[36] Utsumi, T.; Mizuta, T.; Fujii, Y.; Shiono, H.; Okumura, M.; Minami, M.; Takeda, S.; Miyoshi, S.; Matsuda, H. Nitric oxide production by bronchoalveolar cells during allograft rejection in the rat. Transplantation, 1999, 67, 1622-1626.

[37] Sun, J.; Steenbergen, C.; Murphy, E. S-nitrosylation: NO-related redox signaling to protect against oxidative stress. Antioxid. Redox. Signal, 2006, 8, 1693-1605.

[38] Hess, D.T.; Matsumoto, A.; Nudelman, R.; Stamler, J.S. Snitrosylation: spectrum and specificity. Nat. Cell. Biol., 2001, 3, E46-49.

[39] Melino, G.; Bernassola, F.; Knight, R.A.; Corasaniti, M.T.; Nistico, G.; Finazzi-Agro, A. S-nitrosylation regulates apoptosis. Nature, 1997, 388, 432-433.

[40] Thomson, L.; Gadelha, F.R.; Peluffo, G.; Vercesi, A.E.; Radi, R. Peroxynitrite affects $\mathrm{Ca}^{2+}$ transport in Trypanosoma cruzi. Mol. Biochem. Parasitol., 1999, 98, 81-91.

[41] Rubbo, H.; Denicola, A.; Radi, R. Peroxynitrite inactivates thiolcontaining enzymes of Trypanosoma cruzi energetic metabolism and inhibits cell respiration. Arch. Biochem. Biophys., 1994, 308, 96-102.

[42] Ascenzi, P.; Salvati, L.; Bolognesi, M.; Colasanti, M.; Polticelli, F.; Venturini, G.; Inhibition of cysteine protease activity by NOdonors. Curr. Protein Pept. Sci., 2001, 2, 137-153.

[43] McKerrow, J.H. Development of cysteine protease inhibitors as chemotherapy for parasitic diseases: insights on safety, target validation, and mechanism of action. Int. J. Parasitol., 1999, 29, 833-837.

[44] Rao, M.B.; Tanksale, A.M.; Ghatge, M.S.; Deshpande. V.V. Molecular and biotechnological aspects of microbial proteases. Microbiol. Mol. Biol. Rev., 1998, 62, 597-535.

[45] Liaudet, L.; Soriano, F.G.; Szabo, C. Biology of nitric oxide signaling. Crit. Care Med., 2000, 28, N37-52.

[46] Pacher, P.; Beckman, J.S.; Liaudet, L. Nitric oxide and peroxynitrite in health and disease. Physiol. Rev., 2007, 87, 315324

[47] Szabo, C.; Ischiropoulos, H.; Radi, R. Peroxynitrite: biochemistry, pathophysiology and development of therapeutics. Nat. Rev. Drug Discov., 2007, 6, 662-680.

[48] Marnett, L.J.; Riggins, J.N.; West, J.D. Endogenous generation of reactive oxidants and electrophiles and their reactions with DNA and protein. J. Clin. Invest., 2003, 111, 583-593.

[49] Bundy, R.E.; Marczin, N.; Chester, A.H.; Yacoub, M. A redoxbased mechanism for nitric oxide-induced inhibition of DNA synthesis in human vascular smooth muscle cells. $\mathrm{Br} . \mathrm{J}$. Pharmacol., 2000, 129, 1513-1521.

[50] Kim, Y.M.; Son, K.; Hong, S.J.; Green, A.; Chen, J.J.; Tzeng, E.; Hierholzer, C.; Billiar, T.R.; Inhibition of protein synthesis by nitric oxide correlates with cytostatic activity: nitric oxide induces phosphorylation of initiation factor eIF-2 alpha. Mol. Med., 1998, 4, 179-190.

[51] Napoli, C.; Ignarro, L.J. Nitric oxide-releasing drugs. Annu. Rev. Pharmacol. Toxicol., 2003, 43, 97-23.

[52] Bocedi, A.; Gradoni, L.; Menegatti, E.; Ascenzi, P. Kinetics of parasite cysteine proteinase inactivation by NO-donors. Biochem. Biophys. Res. Commun., 2004, 315, 710-718.

[53] Kroncke, K.D.; Suschek, C.V.; Kolb-Bachofen, V. Implications of inducible nitric oxide synthase expression and enzyme activity. Antioxid. Redox. Signal, 2000, 2, 585-605.

[54] Johann, A.M.; Barra, V.; Kuhn, A.M.; Weigert, A.; von Knethen, A.; Brune, B. Apoptotic cells induce arginase II in macrophages, thereby attenuating NO production. FASEB. J., 2007, 21, 27042712.

[55] Freire-de-Lima, C.G.; Nascimento, D.O.; Soares, M.B.; Bozza, P.T.; Castro-Faria-Neto, H.C.; de Mello, F.G.; DosReis, G.A.; Lopes, M.F. Uptake of apoptotic cells drives the growth of a pathogenic trypanosome in macrophages. Nature, 2000, 403, 199203.
[56] Liu, J.; Waalkes, M.P. Nitric oxide and chemically induced hepatotoxicity: beneficial effects of the liver-selective nitric oxide donor, V-PYRRO/NO. Toxicology, 2005, 208, 289-297.

[57] Silva, J.S.; Vespa, G.N.; Cardoso, M.A.; Aliberti, J.C.; Cunha, F.Q. Tumor necrosis factor alpha mediates resistance to Trypanosoma cruzi infection in mice by inducing nitric oxide production in infected gamma interferon-activated macrophages. Infect. Immun. 1995, 63, 4862-7.

[58] Durand, J.L.; Mukherjee, S.; Commodari, F.; De Souza, A.P Zhao, D.; Machado, F.S.; Tanowitz, H.B.; Jelicks, L.A. Role of NO synthase in the development of Trypanosoma cruzi-induced cardiomyopathy in mice. Am. J. Trop. Med. Hyg., 2009 May, 80 (5), 782-787.

[59] Borges, C.R.; Rodrigues, Junior. V.; dos Reis, M.A.; Castellano, L.R.; Chica, J.E.; Pereira, S.A.; Santos, E.; Rodrigues, D.B. Role of nitric in the development of cardiac lesions during the acute phase of experimental infection by Trypanosoma cruzi. Rev. Soc. Bras. Med. Trop., 2009, 42(2), 170-174.

[60] Ascenzi, P.; Bocedi, A.; Gentile, M.; Visca, P.; Gradoni, L. Inactivation of parasite cysteine proteinases by the NO-donor 4(phenylsulfonyl)-3-((2-(dimethylamino)ethyl)thio)-furoxan oxalate. Biochim. Biophys. Acta, 2004, 1703(1), 69-77.

[61] Ascenzi, P.; Bocedi, A.; Gradoni, L. The anti-parasitic effects of nitric oxide. IUBMB. Life., 2003, 55, 573-8

[62] Shiloh, M.U.; Nathan, C.F. Reactive nitrogen intermediates and the pathogenesis of salmonella and mycobacteria. Cur. Opin. Microbiol., 2000, 1, 35-42.

[63] Gradoni, M. L.; Mattu, M.; Persichini, T.; Salvati, L.; Venturini, G.; Ascenzi, P. Molecular bases for the anti-parasitic effect of NO (review). Int. J. Mol. Med., 2002, 131-134.

[64] Silva, J.S.; Machado, F.S.; Martins, G.A. The role of nitric oxide in the pathogenesis of Chagas disease. Front. Biosci., 2003, 314-325.

[65] Lewis, N.D.; Asim, M.; Barry, D.P.; Singh, K.; de Sablet, T.; Boucher, J.L.; Gobert, A.P.; Chaturvedi, R.; Wilson, K.T. Arginase II restricts host defense to Helicobacter pylori by attenuating inducible nitric oxide synthase translation in macrophages. J. Immunol., 2010, 184, 2572-82.

[66] Buscaglia, C.A.; Campo, V.A.; Frasch, A.C.; Di Noia, J.M. Trypanosoma cruzi surface mucins: host-dependent coat diversity. Nat. Rev. Microbiol., 2006, 4(3), 229-236.

[67] Camargo, M.M.; Almeida, I.C.; Pereira, M.E.; Ferguson, M.A Travassos, L.R.; Gazzinelli, R.T. Glycosylphosphatidylinositolanchored mucin-like glycoproteins isolated from Trypanosoma cruzi trypomastigotes initiate the synthesis of proinflammatory cytokines by macrophages. J. Immunol., 1997, 158(12), 5890-5901.

[68] Ciccarelli, A.; Araujo, L.; Batlle, A.; Lombardo, E. Effect of haemin on growth, protein content and the antioxidant defence system in Trypanosoma cruzi. Parasitology, 2007, 134, 959-965.

[69] Silva, J.J.; Osakabe, A.L.; Pavanelli, W.R.; Silva, J.S.; Franco, D.W. In vitro and in vivo antiproliferative and trypanocidal activities of ruthenium NO donors. Br. J. Pharmacol., 2007, 152, 112-2.

[70] Silva, J.J.; Pavanelli, W.R., Pereira, J.C.M.; Silva, J.S.; Franco, D.W. Experimental chemotherapy against Trypanosoma cruzi infection using ruthenium NO-donors. Antimicrob. Agents Chemother., 2009, 6, 1-11.

[71] Colasanti, M.; Gradoni, L.; Mattu, M.; Persichini, T.; Salvati, L.; Venturini, G.; Ascenzi, P. Molecular bases for the anti-parasitic effect of NO. Intern. J. Mol. Med., 2002, 9, 131-134.

[72] Isobe, K.; Nakashima, I. Abundant production of nitric oxide from murine macrophages by direct stimulation of tumor cells. Biochem. Biophys. Res. Commun., 1993, 192, 499-504.

[73] Cardillo, F.; Voltarelli, J.C.; Reed, S.G.; Silva, J.S. Regulation of Trypanosoma cruzi infection in mice by gamma interferon and interleukin-10: the role of NK cell. Infect. Immun., 1996, 64, 128134.

[74] Alibert, J.C.; Machado, F.S.; Souto, J.T.; Campanelli, A.P Teixeira, M.M.; Gazzinelli, R.T.; Silva, J.S. Beta Chemokines enhance parasite uptake and promote nitric oxide-dependent microbiostatic activity in murine inflammatory macrophages infected with Trypanosoma cruzi. Infect. Immun., 1999, 67, 4819-4826.

[75] Machado, F.S.; Martins, G.A.; Aliberti, J.C.S.; Mestriner, F.L.A.; Cunha, F.Q.; Silva, J.S. Trypanosoma cruzi-infected cardiomuocytes produce chemokines and cytokines that trigger potent nitric oxide-dependent trypanocidal activity. Circulation, 2000, 102, 3003-3008. 
[76] Silva, J.S.; Twardizik, D.R.; Reed, S.G. Regulation of Trypanosoma cruzi infections in vitro and in vivo by transforming growth factor beta (TGF-beta). J. Exp. Med., 1991, 174, 539-545.

[77] Maya, J. D.; Cassels, B.K.; Itturriaga-Vasquez, P.; Ferreria, J.; Faúdez, M.; Galanti, N.; Ferreira, A.; Morello, A. Mode of action of natural and synthetic drugs against Trypanosoma cruzi and their intarection with mammalian host. Comp. Biochem. Physiol. Part A. Physiol., 2007, 146, 601-620.

[78] Martins, G.A.; Cardoso, A.G.; Aliberti, J.C.S.; Silva, J.S. Nitric oxide-induced apoptotic cell death in the acute phase of Trypanosoma cruzi infection in mice. Immunol. Lett., 1998, 63, 113-120.

(C) Pavanelli and Silva; Licensee Bentham Open.

This is an open access article licensed under the terms of the Creative Commons Attribution Non-Commercial License (http://creativecommons.org/licenses/by-nc/3.0/) which permits unrestricted, non-commercial use, distribution and reproduction in any medium, provided the work is properly cited. 